\title{
Research on "Rotten Feet" Phenomenon in Cast-in-place Reinforced Concrete Columns of Liu Lu Apartment
}

\author{
Shouyong Zhao \\ College of Civil Engineering, Sichuan Agricultural University, Dujiangyan, Sichuan Province, China
}

Keywords: Drain Holes; Exposed Reinforcement; Prevention; Treatment Measures.

\begin{abstract}
Rotten feet" phenomenon, represented by drain holes and exposed reinforcement, occurs in the cast-in-place concrete columns of Liu Lu Apartment. This paper analyzes the reasons of this phenomenon. Main reasons include concrete disintegration, which is represented by mortar and gravel separation; too much concrete unloading at one-time and inadequate vibration; inappropriate selection of concrete mix ratios and others. Corresponding preventive ways and countermeasures are provided in this paper. These methods of prevention and treatment are also applicable to drain holes and exposed reinforcement in beams and plates.
\end{abstract}

\section{Introduction}

After the "5.12" earthquake, the safety of buildings has received unprecedented attention. However, "rotten feet" phenomenon occurs in the cast-in-place concrete columns of Liu Lu Apartment. Most cases happen in the weak link of cast-in-place frame buildings, namely the construction joints of reinforced concretes between the upper layer and the lower layer. [1] Without proper treatments, they will affect the integrity, as well as the seismic performance of the building, and the lateral stiffness of the frame. [2] Thus, the "rotten feet" phenomenon should be prevented during the process of concreting.

\section{Brief Introduction of the Project}

Liu Lu Apartment covers an area of $2.4 \mathrm{mu}$, and is planned as one of the reconstruction projects after the disaster. It is a residential building with total height of $17.9 \mathrm{~m}$. The ground floor is designed as a garage; upper 5 floors include 4 units and total 40 households. Liu Lu Apartment adopts the overall cast-in-place frame structure, with 8 degree of seismic fortification intensity, second grade, 50 years of building endurance period, second degree of building fire resistance, and second degree of construction engineering design.

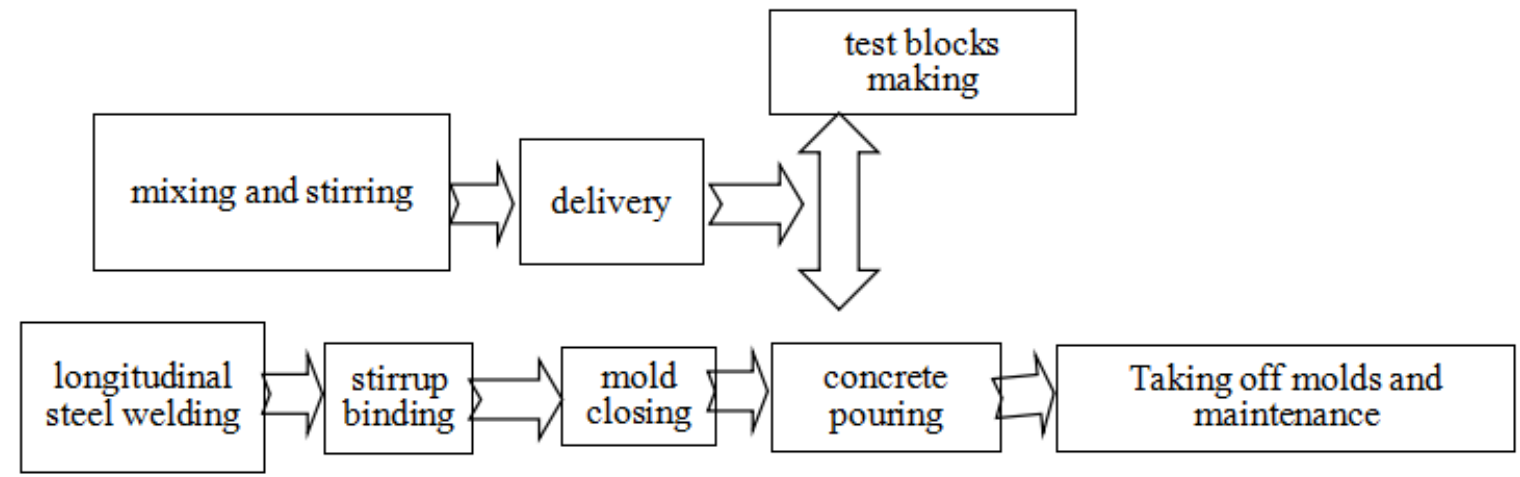

\section{Construction Technique and Technological Process of Concrete Columns of Liu Lu Apartment}

Pump concrete technique is adopted in this project; the mainly used concrete is marked as C30. 
Inserted vibrator is used in vibratory compaction. The early strength agent triethanolamine [ $\mathrm{N}$ $(\mathrm{C} 2 \mathrm{H} 4 \mathrm{OH})$ ], which has no corrosive effects on the reinforcement (steel bars), is added to concrete at the ratio of $0.005 \%$. Triethanolamine $[\mathrm{N}(\mathrm{C} 2 \mathrm{H} 4 \mathrm{OH})]$ is hardened at room temperature and can reach $50 \%$ of design strength in 5 to 7 days. [3] The construction process of cast-in-place columns is shown as the following chart.

Beams and plates have different construction process. In order to facilitate the reinforcement, rebar binding comes before the mold closing process of beams and plates.

\section{The Main Performances and Damage of Rotten Feet}

\subsection{The main performances of rotten feet.}

The main performances of rotten feet are drain holes and exposed reinforcement. Drain holes means defects on the surface of concrete; the thickness of these defects lies between the thickness of protective layer and 1 / 3 of the section size. [4] As the holds are deeper than the protective layer, the main reinforcement cannot be wrapped by concrete anymore; exposed reinforcement occurs accordingly.

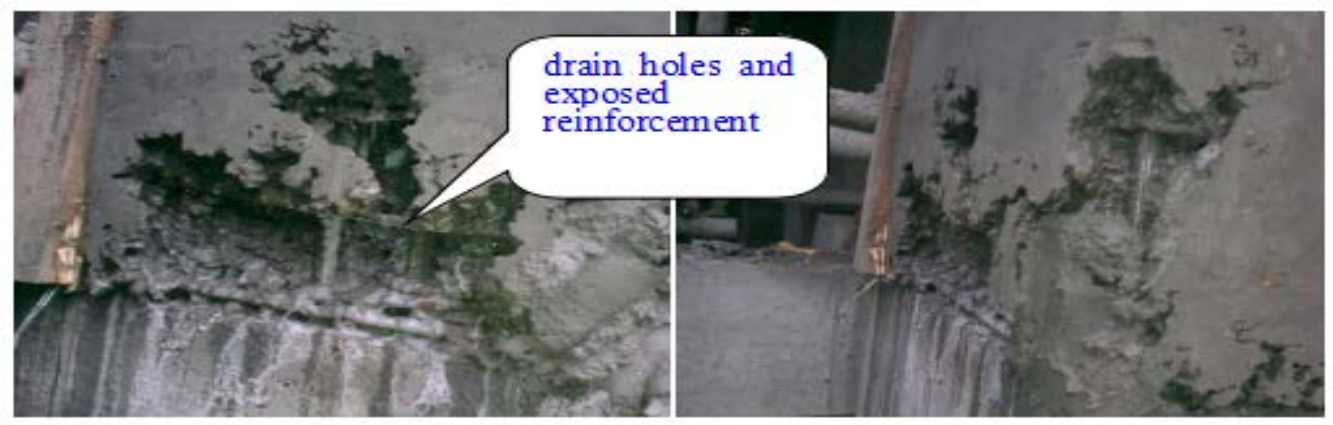

\subsection{The damage of rotten feet.}

Rotten feet make the surface of concrete columns uneven, which affects the overall beauty of the building, and makes residents feel insecurity. Air can contact with steels and make them rust through chemical reaction. The response equation is: $3 \mathrm{Fe}+2 \mathrm{O} 2=\mathrm{Fe} 3 \mathrm{O} 4$. Rotten feet harm the safety, durability, robustness and reliability of the building. [5]

\section{Reason Analyses}

\subsection{Concrete disintegration; mortar separated from stones.}

In the transportation process, some roads are uneven. Transport vehicles may not rotate the concrete tank slowly according to provisions, and lead to the separation of mortar and gravel, which is mainly represented by gravel sinking. After delivery to the construction site, concrete without stirring may be directly poured to the building through the pump truck. At that time, stones do not contain mortar. When stones fall to the root of columns, some parts are still empty. Without enough vibration, the mortar cannot flow into the gap between stones, resulting in exposed reinforcement or drain holes.

According requirements, before concreting through pump truck, a certain amount of mortar should be poured into the pipe to clear the pipe. [6] This process has two purposes. One purpose is to protect the pipeline; when gravels contact the inner wall of pipeline, the damage of smooth, wet wall is much less than the dry wall. The other purpose is to prevent concrete segregation. Dry internal wall of pipeline can absorb water and sand slurry from the concrete during pouring. But this kind of situation occurs only at the beginning stage of pouring. In the following stages, the pipeline contains enough water and mortar; this phenomenon disappears.

\subsection{Non-standard operation.}

Non-standard operation mainly refers to too much concrete unloading at one-time and inadequate 
vibration. [7] The structure of each layer is 3 meters high. In this project, column concreting method is one-time concrete pouring; then inserted vibrators are used. At the construction scene, the vibration was made at only one diagonal point. The worker vibrated and pulled up; pouring was a one-time process, while vibration was also one-time process. The vibration was made at only one diagonal point. This operation inevitably leads to following situations: columns are not filled with concrete; some stones are stuck on the steel bar and prevent subsequent gravel and mortar; drain holes and exposed reinforcement occur. [8]

\subsection{Improper selection of materials and mixing ratios.}

Stones are too large and stuck in the reinforcement. The choice of coarse aggregate should strictly accord with the requirements of design size. The problem is show in the picture below. Large stones are easily to be stuck and result in unnecessary losses. Moreover, when concreting, stones are stuck, or even lie on steel bars, blocking following stones and mortar, and leading to drain holes and exposed reinforcement.

Improper water cement ratio. The construction water cement ratio and mix proportion should be adjusted according to the moisture content of raw materials on the basis of design water cement ratio and mix proportion. [9] In construction, the water cement ratios of different parts are different. For instance, the water cement ratio of other parts is higher than that of sloping roofs and stairs. [10] This is because the "slanting" construction of stairs and sloping roofs. If water cement ratio is too high, the concrete fluidity will be too strong to pouring molding. Low water cement ratio is conducive to rapid pouring molding.

After pouring the stairs, workers did not add water to the tank to dilute the concrete; they poured the concrete directly into other places, such as columns. Due to the low liquidity and less water content, concrete could not flow after falling; small holes appeared at the foot of column.

\subsection{Other reasons.}

The following operations can also give rise to rotten feet. Concrete materials are stuck at the rebar parts, reserved holes or embedded parts, and are not vibrated properly; then upper layer concrete is poured directly.[11] Before pouring, debris like furniture pieces, wood, mud and other materials are easily to fall into the concrete. Usually, workers do not timely clean the debris, and pour the concrete directly into steel bars. In embedded parts and places with high density of reinforcing steel, concrete pouring is not smooth. Concrete cannot fill all the spaces of template. If the vibration is not carried out according to proper order, some parts will be left out. Serious slurry loss, disorganized engineering construction and non-standard operation can also lead to rotten feet. [12]

\section{Control Measures}

\subsection{Preparation before concreting.}

Material selection should be carried out strictly according to requirements. Generally speaking, stones ought to be gravels or pebbles of $4.75 \sim 40 \mathrm{~mm}$ diameter. When the pumping height is more than $50 \mathrm{~mm}$, the maximum size of gravel particle should not exceed $25 \mathrm{~mm}$, and the maximum size of pebble particle should not exceed 30mm. In the mixing process, fitting tests should be performed to check the homogeneity of concrete. First, the concrete mixing duration should be no more than 90 minutes; samples should be taken from 1/4 to 3/4 parts of the discharge outflow. Second, after the completion of concrete mixing, samples should also be taken from the mixing and pouring sites to test the consistency. Third, in the detection of slumps, the viscosity and water retention of concrete mixture should also be detected to comprehensively evaluate the workability of concrete mixture. [13] Following points should also be checked. Firstly, opening the cleaning hole before concrete pouring, in order to rinse off residues in the column, mud at the bottom wall, floating sand, pumice, sawdust, waste and other debris with water; then, no water should be left;. Secondly, wood should be watered to become wet. Thirdly, when the template cracks are large, cement bags or paper ashes should be filled; the four corners of templates should be tightly jointed especially. Fourthly, a layer of $5-10 \mathrm{~cm}$ 
cement mortar and concrete components should be put at the bottom of column mould before pouring concrete. [14]

\subsection{Concreting.}

When the column height is no more than $3 \mathrm{~m}$, and the column section is larger than $40 \mathrm{~cm} * 40 \mathrm{~cm}$, and there is no cross stirrup, concrete can be directly poured into the top of column molds. When the column height is more than $3 \mathrm{~m}$, segment pouring process must be adopted. The height of each segment should not exceed 3m.

For concrete columns with section size within $40 \mathrm{~cm} * 40 \mathrm{~cm}$, or columns with cross steel bars, segment pouring must be adopted through slant chutes installed in door holes at the flank side of column molds; the height of each segment should be no more than $2 \mathrm{~m}$. Steel bars located on door holes can be untied and moved upwards temporarily, and then moved to the original position and be sealed again after pouring and closing. When the door hole is closed, another clamp should be used to fix the bars. When unload materials, the chute could be moved from side to side gently to accelerate the process. [15]

\subsection{Vibration of concrete.}

When one segment of column is completely poured, the inserted vibrator needs to from the top of columns (for convenient operation, flexible shaft should be 0.5 - $1 \mathrm{~m}$ longer than the column). If the vibrator is shorter than the column, it should be inserted into the column from the side door hole.

When using the inserted vibrator, the worker should stretch one of his hands into the door and make the hose below this hand vertical; the other hand should hold the hose behind and lift the hose to close to the template, in order to prevent hard bending at the turning point. After finding the vibration point, another person should turn on the switch and start vibration.

When the length of vibrator flexible shaft is more than $3 \mathrm{~m}$, the flexible hose should swing and contact with steel bars in the process of vibration. Therefore, the vibration point needs to be found before inserting the vibrator and turning on the switch. When the concrete is no longer collapsed, thick liquid can be seen, and workers can see light from the top to the down, the vibrator can be removed. The switch should be turned off immediately to stop vibration, and then the vibrator can be slowly taken out of the column.

When the section of the column is relatively small and the reinforcement is relatively intensive, horizontal template can be adopted at one side of the column. From the bottom to the top, the template of each section should be closed after concreting. This approach can facilitate the vibration and compaction of concrete. [16]

When pouring concrete, the process should be divided into column segments and proceeding continuously. The height of each segment should be determined according to concrete supply capacity, the amount of pouring at one time, the initial setting time of concrete, the structural characteristics and the reinforcement density. It is generally 1.25 times of the length of the function part of the vibrator. The vibrator should be inserted quickly and pulled out slowly; the insertion points should be arranged evenly; the process should be done in sequence of every point, and no point should be omitted, so as to achieve the uniform vibration. The moving distance should be no more than 1.5 times of the vibrating radius (generally $30-40 \mathrm{~cm}$ ). When the upper layer is vibrated, the lower layer should be inserted at $5-10 \mathrm{~cm}$, so that the two layers of concrete can be bonded firmly. When vibrating, the vibrator shall not touch steel bars and the template.

The concreting shall be carried out continuously. In cases of necessary breaks, break time should be as short as possible; workers should complete the secondary layer concrete pouring before solidifying the preliminary layer. The longest period of breaks should be determined according to cement varieties, temperature and concrete setting conditions. Generally speaking, the construction joints should be treated if the duration is more than $2 \mathrm{~h}$. When the setting time of concrete is less than $2 \mathrm{~h}$, the initial setting time of concrete should be performed. The moving distance of inserted vibrator should be no greater than 1.5 times its function radius; vibrator template distance should be no greater than $1 / 2$ of the vibrator radius; workers should try to avoid the collision of reinforcement, templates and buried pipes; the vibrator should be inserted into the lower concrete at $5 \mathrm{~cm}$. [17] 


\subsection{Countermeasures for formed drain holes and exposed reinforcement.}

Countermeasures for formed drain holes and exposed reinforcement go as following: removing weak parts and protruding parts, then inclining upper parts outwards and keeping lower parts level; rinsing the base with high pressure water and brush it with steel wire; before repairing, filling cracks and holes with wet sacks or wet cotton yarn to make the old concrete surface moist; choosing the same kind of cement concrete for repairing according to the original building cement, and making strength grade of small stones higher than the original level. If conditions permit, sprayed concrete repair can be used. Template concreting should be installed; a small amount of expansion agents can be added; when pouring; outside part should be slightly higher than the repairing part; outward inclined surface should be removed when repaired parts meet the structural design strength. [18]

\subsection{Applications in other parts of the structure.}

Apart from columns, buildings also have beams and plates. The same rotten feet phenomenon can also appear in beams and plates. Related reason and processing measures are also similar. Therefore, the column "rotten feet" prevention and treatment methods can be used in other parts of the building's main body. It can be concluded that when the problem of column "rotten feet" is solved, the same problem of other parts of the construction can also be addressed.

\section{Conclusions}

Reliable is the most important requirement for building structures. In this paper, analysis on "rotten feet" in cast-in-place reinforced concrete columns and measures are provided through author's reflection and opinions from workers in the construction site. Criticisms for deficiencies are warmly welcome. The only purpose of this paper is academic exchange, which is also the reason of not mentioning the specific location of this project.

\section{References}

[1] Southeast University, Tongji University, Tianjin University, Concrete Structure (Volume One): Principles of Concrete Structure Design, fourth ed., Tsinghua University (Eds.), China Architecture \& Building Press, Beijing, 2008.

[2] Southeast University, Tongji University, Tianjin University, Concrete Structure (Volume Two): Concrete Structure and Masonry Structure Design, fourth ed., Tsinghua University (Eds.), China Architecture \& Building Press, Beijing, 2008.

[3] H.Q. Mao, Building Construction. China Architecture \& Building Press, Beijing, 1997.

[4] National Standard of People's Republic of China. Standards for Construction and Acceptance of Reinforced Concrete Works, GBJ2004 - 83.5 - 6.

[5] L.P. Ye, Concrete Structure. Tsinghua University Press, Beijing, 2000.

[6] [15] S.W. Wang, A Collection of Translated Essays on Concrete Quality Control, China Industry Press, Beijing, 1965.

[7] S. Ming, Q.Q. Fang, et al. (Trans.), Concrete. China Architecture \& Building Press, Beijing, 1989, pp.144 - 147.

[8] H.J. Shi, Influencing factors and control measures of concrete construction quality, J. Modern Enterprise Culture. 09 (2009).

[9] H.Q. Mao (Eds.), Construction of Civil Engineering, third ed., Wuhan University of Technology Press, Wuhan, 2009.

[10] J.H. Zheng, Quality of concrete construction, J. New Technology and New Products of China. 15 (2009). 
[11] P.J. Cong, Management Manual for Practical Engineering Projects, China Architecture \& Building Press, Beijing, 2007.

[12] X.Q. Kong, Prevention and treatment of concrete cracks, J. Jilin Water Resources. 12 (2004) 46 $-47$.

[13] D.Q. Li, J.G. Li, Causes and prevention measures of freeze-thaw damage of concrete, J. Water Conservancy. 12 (2004).

[14] L.K. Yang, W.G. Zhou, Some opinions on concrete construction, J. Management \& Technology of SME. 18 (2009)

[16] J.P. Li, Concrete construction, J. Management \& Technology of SME. 04 (2010)

[17] National Standard of People's Republic of China, Standards for design of Concrete Structures. GB500102002. China Architecture \& Building Press, Beijing, 2002.

[18] J.H. Zheng, Concrete, J. New Technology and New Products of China. 04 (2010). 